\title{
A proteção das crianças na internet: uma reflexão sobre as responsabilidades parentais e o fenómeno sharenting
}

https://doi.org/10.21814/uminho.ed.30.9

\author{
Daiane Pompeo Barcelos \\ Mestranda em Direito das Crianças, Família e Sucessões da EDUM \\ Larissa Franzoni \\ Mestranda em Direito das Crinaças, Família e Sucessões da EDUM
}

\section{Introdução}

O mundo digital já é quase um imperativo existencial e pouco se vislumbra a vida quotidiana sem algum tipo de intermediação dos recursos tecnológicos e da internet. Neste cenário, faz-se premente a discussão acerca da proteção dos direitos das crianças no universo online.

Por a proteção da criança na internet configurar um tema amplo, merecedor de um estudo aprofundado que a dimensão deste texto não permitirá, no presente estudo procura-se apenas analisar as responsabilidades parentais e a utilização das redes sociais pelos progenitores, quando esse uso implicar publicações relativas à vida dos filhos.

O trabalho será analisado à luz do ordenamento jurídico português e da perspectiva europeia sobre o tema. Para alcançar esta reflexão, parte-se da análise das responsabilidades parentais enquanto veículo de atendimento ao superior interesse da criança. Passa-se, então, ao apontamento das garantias dos direitos fundamentais da criança, com ênfase nos direitos de personalidade ligados à privacidade e à imagem. Por fim, analisam-se as questões referentes ao dever dos pais de proteção dos direitos fundamentais da criança na internet.

\section{Considerações sobre as responsabilidades parentais e o superior interesse da criança}

As responsabilidades parentais não são mais compreendidas como um poder, que em outros tempos se manifestava como um direito de posse e disposição paternal (no sentido patriarcal da organização familiar) quanto às questões relativas à pessoa, bens e direitos dos filhos. Desta forma, o legislador alterou a designação prevista no Código Civil Português ${ }^{1}$, substituindo "poder paternal" por "responsabilidades

1 Art. 3. ${ }^{\circ}$ da Lei n. ${ }^{\circ}$ 61/2008, de 31 de outubro. 
parentais", resultando em uma mudança no enfoque do objeto da norma, que passou "a estar não naquele que detém o 'poder' - o adulto, neste caso - mas naqueles cujos direitos se querem salvaguardar, ou seja, as crianças".

A mudança na designação trazida pela lei ocorreu em razão de que a anterior expressão, "poder paternal", estabelecia-se na desigualdade entre o pai e a mãe, na medida em que era pautada no poder do pai, chefe da família, e também na condição dos filhos como objetos de direito, e não sujeitos ${ }^{3}$.

A noção hodierna de responsabilidades parentais inverte esta lógica histórica, e passa a corresponder a um poder-dever de caráter altruísta, atendendo ao superior interesse da criança, considerando-se a criança como um indivíduo em condição peculiar de pessoa em desenvolvimento, destinatária dos esforços máximos do Estado e da família para a garantia de sua dignidade. Portanto, para além de um direito, as responsabilidades parentais configuram-se em verdadeiros deveres e obrigações, na maioria das vezes impostas pela própria legislação ${ }^{4}$.

Feitas tais considerações, insta mencionar em quais obrigações legais consistem as responsabilidades parentais e como a legislação portuguesa regula o seu exercício nas diferentes configurações familiares.

Neste particular, salienta-se que as responsabilidades parentais estão previstas na Constituição da República Portuguesa, no seu art. $36 .^{\circ}$, n. 5 , e são disciplinadas pelos arts. $1877 .^{\circ}$ e segs. do Código Civil. Da análise do conteúdo das normas, observa-se que as responsabilidades parentais nascem de forma automática, são indisponíveis a partir da filiação e objetivam suprir as necessidades dos filhos menores e não emancipados.

0 art. $1878 .^{\circ}$ do Código Civil determina que "compete aos pais, no interesse dos filhos, velar pela segurança e saúde destes, prover ao seu sustento, dirigir a sua educação, representá-los, ainda que nascituros, e administrar os seus bens." E que os pais, "de acordo com a maturidade dos filhos, devem ter em conta a sua opinião nos assuntos familiares importantes e reconhecer-lhes autonomia na organização da própria vida."

O exercício destas incumbências, como mencionado, não é livre. De facto, a própria Constituição da República Portuguesa acautela quanto a abusos no exercício destes direitos (art. 69..$^{\circ}$, n. 1), prevendo até mesmo a possibilidade de afastamento de progenitor (art. 36. ${ }^{\circ}$, n. 6) pela inibição do exercício da responsabilidade parental.

Verifica-se, assim, que o exercício das responsabilidades parentais está vinculado ao interesse das crianças, o qual, todavia, não pode ser exercido livremente e de forma arbitrária, especialmente porque, além de constituir um poder-dever conformado

2 DIAS, Cristina - Uma Análise do Novo Regime Jurídico do Divórcio - Lei n. ${ }^{\circ}$ 61/2008, de 31 de outubro. 2. ${ }^{a}$ edição, Coimbra: Almedina, 2009, p. 42.

3 RODRIGUES, Hugo Manuel Leite - Questões de Particular Importância no Exercício das Responsabilidades Parentais. 1. ${ }^{a}$ edição, Coimbra: Coimbra Editora, 2011, p. 18.

4 Neste sentido: DIAS, Cristina - A Criança como Sujeito de Direitos e o Poder de Correcção. "Julgar", n. ${ }^{\circ} 4$, Coimbra, 2008, pp. 87/101; LÔBO, Paulo - Direito Civil: Famílias. 4. ${ }^{a}$ edição, São Paulo: Saraiva, 2011, pp. 295/299, e SOTTOMAYOR, Maria Clara - Regulação do Exercício das Responsabilidades Parentais nos Casos de Divórcio. Coimbra: Edições Almedina, 2011, pp. 17/23. 
pela legislação, tem como fim a proteção das crianças, que deixaram de ser consideradas mero objeto de proteção, e passaram a ser vistas como sujeitos de direitos.

\section{A criança enquanto sujeito de direitos e os direitos fundamentais relativos à personalidade}

Embora atualmente se entenda que toda e qualquer pessoa humana, independentemente de sua idade, ascendência, sexo, raça, língua, território de origem, religião, convicções políticas ou ideológicas, instrução, situação económica, condição social ou orientação sexual ${ }^{5}$, seja titular de direitos humanos e direitos fundamentais, especificamente no que tange às crianças, o caminho de reconhecimento do status de sujeito de direitos até a consolidação de direitos humanos específicos apresentou-se mais longo, e ainda em processo de consolidação6.

Somente no século XX é que se estabeleceram os direitos humanos pensados de forma específica às crianças e adolescentes na esfera internacional, com a aprovação da Convenção sobre os Direitos da Criança, de 1989, pela Assembleia Geral das Nações Unidas. Neste ato, consagraram-se os direitos da criança consubstanciados nos princípios fundamentais da não discriminação (art. $2 .^{\circ}$ ), do superior interesse da criança (art. $3^{\circ}$ ), do direito à vida, à sobrevivência e ao desenvolvimento (art. $6^{\circ}$ ) e do respeito às opiniões da criança (art. 12.\%). Atualmente, 196 (cento e noventa e seis) países ratificaram e internalizaram estas normas de proteção à infância ${ }^{7}$.

Acerca da Convenção sobre os Direitos da Criança, Maria Clara Sottomayor leciona que é este o documento internacional que "reflete a especificidade da infância, concebendo, de forma inovadora, a criança como pessoa titular de direitos e liberdades fundamentais, com o direito de participar nas decisões que the dizem respeito"8.

Em Portugal, sobre o direito à personalidade, o art. $700^{\circ}$ do Código Civil prevê a proteção dos indivíduos contra qualquer ofensa ilícita ou ameaça de ofensa à sua personalidade física ou moral, bem como dispõe que, independentemente da responsabilidade civil a que haja lugar, a pessoa ameaçada ou ofendida pode requerer as providências adequadas às circunstâncias do caso, com o fim de evitar a consumação da ameaça ou atenuar os efeitos da ofensa já cometida. Portanto, nota-se que os poderes jurídicos do sujeito ativo dos direitos de personalidade incidem de forma

5 Conforme princípio da igualdade, nos termos previstos pelo art. $13^{\circ}$, 2. da Constituição da República Portuguesa (doravante abreviada para CRP). No texto, para efeitos do desenvolvimento do tema, acrescentou-se o elemento "idade" ao rol extraído do texto constitucional.

6 BOLIEIRO, Helena; GUERRA, Paulo - A Criança e a Família: uma questão de direito(s) - visão prática dos principais institutos do direito da família e das crianças e jovens. 2. ${ }^{a}$ edição, Coimbra: Coimbra Editora, 2014, pp. 13/20.

7 UNICEF, Convenção Sobre os Direitos da Criança. [consultado em 2021-04-30]. Disponível na WWW: < https://www.unicef.org/brazil/convencao-sobre-os-direitos-da-crianca>.

8 SOTTOMAYOR, Maria Clara - Temas de Direito das Crianças. Coimbra: Almedina, 2014, pp. 52/53. 
plena caracterizando-se, assim, como absolutos, exigíveis em face de qualquer pessoa, e oponíveis erga omnes?

O direito à imagem possui especial previsão no art. $26 .^{\circ}$, n. $^{\circ} 1$ da Constituição da República Portuguesa e no art. $79 .^{\circ}$ do Código Civil. Este último, dispõe que a divulgação, reprodução e comercialização do retrato de uma pessoa dependerá do seu prévio consentimento, sendo dispensável somente em situações em que a notoriedade da pessoa retratada, o cargo que desempenhe, as exigências de polícia ou de justiça, as finalidades científicas, didáticas ou culturais justifiquem tal medida, ou, ainda, quando a reprodução da imagem vier enquadrada na de lugares públicos, na de factos de interesse público ou que haja decorrido publicamente. Já o n. 3 do referido dispositivo veda a divulgação de retratos que possam resultar em prejuízo a honra, reputação ou simples decoro da pessoa retratada.

Partindo da premissa de que o exercício das responsabilidades parentais tem como baliza o superior interesse da criança e considerando o arcabouço protetivo dos direitos fundamentais e dos de personalidade, impõe-se a conclusão de que estes direitos, pelo caráter de essencialidade à configuração da dignidade humana, devem ser respeitado pela família, em especial pelos progenitores, que detém o poder-dever de promoção dos mesmos.

Neste sentido, a proteção da honra, imagem, privacidade e intimidade das crianças ganha importância, quando colocado em causa o uso dos espaços virtuais na vida quotidiana, notadamente as redes sociais. Os progenitores não dispõem dos direitos fundamentais e dos direitos de personalidade dos filhos, e a natureza do funcionamento da internet e da transmissão de informações revela a necessidade de se tomar cuidado na maior medida possível, evitando condutas que possam representar a violação aos direitos da criança.

\section{O fenómeno sharenting e a ciberproteção das crianças}

Os espaços virtuais originados pela rede mundial de computadores ampliaram as esferas de comunicação e interação humana, inaugurando novos desafios às famílias. Especificamente em relação ao direito à imagem, tornou-se habitual que os progenitores compartilhem fotos dos seus filhos nas redes sociais. Questiona-se efetivamente o interesse da criança em ter sua imagem propagada no espaço cibernético e disponibilizada a um número imensurável de pessoas. Nesse contexto, surgiu o termo "ciberproteção", bem como a expressão da língua inglesa "sharenting", que decorre da união das palavras "share" (compartilhar) e "parenting" (cuidar, no sentido de exercer as responsabilidades parentais).

Sobre o tema, vislumbra-se que os progenitores, ao compartilharem fotos dos filhos na internet, desconheçam a amplitude das publicações, uma vez que esses conteúdos podem perdurar na rede por tempo indeterminado, ainda que excluídos, bastando que sejam salvos ou partilhados por qualquer pessoa que a eles tenha acesso.

9 SOUSA, Rabindranath Valentino Aleixo Capelo de - O Direito Geral de Personalidade. Coimbra: Coimbra Editora, 1995, p. 401. 
Além disso, podem produzir danos irreparáveis aos direitos da personalidade, caso as informações sejam manipuladas ou utilizadas fora de contexto, motivo pelo qual a liberdade de informação exercida nas redes sociais deve ser equilibrada com a responsabilidade pela difusão dos conteúdos veiculados neste espaço ${ }^{10}$.

Não bastasse, os pais também acabam por esquecer que as publicações podem constranger ou desagradar a criança, titular do direito à imagem, quando ela se tornar adulta, podendo, inclusive, ser utilizadas em bullying e, até mesmo, em redes de pornografia infantil.

Assim, os pais devem pensar se aquela publicação traz vantagem ou se beneficia a criança em alguma circunstância. É também razoável averiguar de antemão os possíveis riscos presentes e futuros que a publicação pode representar para as crianças, em especial, se a publicação possui algum caráter vexatório ou humilhante, se identifica rotinas que possam facilitar o acesso à criminosos que tenham crianças como alvo, entre outros. Devem, portanto, abster-se de divulgar imagens do filho, exceto, nos casos em que a divulgação seja de interesse da própria criança ou nos quais exista notoriedade pública que justifique a sua exposição, nos termos do art. 79. ${ }^{\circ}$, n. 2, do Código Civil. Sobre o tema, Rossana Martingo Cruz entende que "a disposição do direito à imagem, sendo um direito de personalidade, será também um direito pessoal que só deverá ser exercido pelos pais em situações de necessidades dos filhos. Ora, em abstrato, não se vislumbra qualquer interesse ou benefício que a criança possa retirar pelo facto da sua imagem ser divulgada, partilhada e quedar-se indefinidamente na internet numa qualquer rede social. Pois, a partir do momento que a imagem é colocada na internet a mesma não desaparecerá facilmente, ainda que apagada por quem a colocou"11.

Nota-se, assim, que a dignidade e os direitos da criança devem ser respeitados em qualquer circunstância, atendendo ao seu superior interesse, devendo, inclusive, as suas opiniões serem tomadas em conta quando a idade permitir que se manifestem ${ }^{12}$.

A publicação da imagem ou da vida íntima das crianças nas redes sociais, quando não objetiva nenhuma espécie de benefício direto às crianças, implica em violação aos direitos fundamentais à privacidade e intimidade, e também aos direitos de personalidade relativos à imagem e reserva da vida privada. Tais direitos, por sua natureza, não estão à disposição dos progenitores, não podem ser violados, dada sua natureza erga omnes e, em especial, devem ser promovidos e protegidos pelos progenitores enquanto detentores de responsabilidades parentais, já que, conforme visto,

10 ALCARAZ, Maria Hylma - Reflexões Sobre a Proteção dos Direitos Fundamentais Dentro do Mundo Digital, in "Direito na Lusofonia. Direito e novas tecnologias". 5. ${ }^{\circ}$ Congresso Internacional de Direito na Lusofonia, Braga: Escola de Direito da Universidade do Minho, Centro de Investigação em Justiça e Governação (Jusgov), 2018, pp. 327/328.

11 CRUZ, Rossana Martingo - A Divulgação da Imagem do Filho Menor nas Redes Sociais e o Superior Interesse da Criança. In "Direito e Informação na Sociedade em Rede - Atas do IV Colóquio Luso-Brasileiro Direito e Informação". Porto, 2016. [consultado em 2021-04-30]. Disponível na WWW: <https://repositorium.sdum.uminho.pt/handle/1822/47936>.

12 UNICEF, Pautas para Cobertura Periodistica sobre Temas de la Niñez y la Adolescencia. [consultado em 2021-04-30]. Disponível na WWW: <https://www.unicef.org/republicadominicana/pautas_tratamiento_>. prensa_FINAL.pdf. 
as responsabilidades parentais correspondem ao atendimento do superior interesse das crianças.

Nessa perspectiva, é imprescindível que os pais façam uma ponderação sobre uso consciente da internet relativamente à divulgação de publicações que envolvam os filhos. Mostra-se fundamental também que os progenitores tenham ciência de que o exercício das responsabilidades parentais não lhes outorga o direito à imagem dos filhos, e que, portanto, não pode ser utilizada de acordo com o livre arbítrio de seus detentores ${ }^{13}$.

\section{Conclusão}

Neste breve estudo procurou-se refletir acerca da proteção dos direitos fundamentais e de personalidade das crianças na internet, tendo como objeto de análise o papel dos progenitores em promover o superior interesse da criança.

É possível verificar que a legislação dá especial relevo aos direitos à intimidade e à vida privada, e preocupa-se mais especialmente com as crianças enquanto destinatários de políticas de proteção, fornecendo legislação específica para o reforço de efetividade dos direitos das crianças.

$\mathrm{Na}$ esfera privada e intrafamiliar, o papel precípuo dos progenitores é o de garantia do superior interesse da criança, de modo que o exercício das responsabilidades parentais deve ser por ele pautado, e conformado pela legislação em vigor. Neste cenário, tendo em vista a imperativa realidade que emerge da internet, faz-se mister a ponderação dos pais quanto ao uso razoável das ferramentas e plataformas tecnológicas, a fim de que não se esteja a vulnerar os direitos fundamentais e de personalidade das crianças.

Não dispondo os pais dos direitos de personalidade dos filhos, é dever dos progenitores a proteção máxima aos direitos das crianças e, ademais, estão também os progenitores sujeitos ao respeito às normas que regulam o uso da internet, normas estas que se ocupam em resguardar os direitos fundamentais e de personalidade de todas as pessoas singulares e, em especial, das crianças.

Neste sentido, para que haja um uso consciente e legalmente adequado da internet relativamente às crianças, é preciso se ter em conta novamente o superior interesse da criança, o respeito aos seus direitos fundamentais, e ponderar acerca dos possíveis riscos advindos da exposição virtual, evitando-se, na medida do possível, a divulgação desnecessária de imagens das crianças nas redes.

13 CAMPOS, Diogo Leite de; CAMPOS, Mónica Martinez de - Lições de Direito da Família. 3. ${ }^{a}$ edição, Coimbra: Almedina, 2017, p. 126. 